\section{Reverse Bloom: A new hybrid approach to experiential learning for a new world}

Journal of Education, Innovation and Communication (JEICOM)

Vol. 2. Issue 2, December 2020 DOI: $10.34097 /$ jeicom-2-2-Dec2020-2

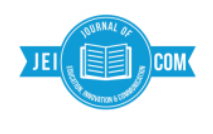

Dr Arthur W Shelley ${ }^{1}$

\begin{abstract}
Bloom's Hierarchy of learning has been the foundation of formal teaching and assessment practice since the mid 1950's. This has resulted in higher-quality education outcomes, more consistency in delivery, and better teaching practices. However, mainstream teaching practices and teacher training have focused on the Cognitive domain, with less focus on social development (except for some societies and non-mainstream institutions). There has been little emphasis on the two other domains for comprehensive learning, which Bloom's colleagues identified as the Psychomotor and Affective domains. These two less used domains highlight the skills and social aspects of being able to influence others and apply the learning in practice to generate value. The imbalance between the three is critical because all three domains play a role in being a competent professional and a contributing member of society, based on the capabilities built in their learning experiences.

This paper shares three key new contributions to the learning literature that help address this imbalance: The "Reverse Bloom Learning Framework" (RBLF), a set of principles to guide learning facilitation through the RBLF, and some insights on design of inclusive learning activities (including provision of deeper feedback for better reflection and higher quality learning outcomes). Together these three elements of progressive learning can enable a more balanced approach to learning at all levels. The RBLF includes all three of Bloom's domains in iterative social learning experiences and reverses the traditional order of Bloom's learning elements. The author suggests this more inclusive and comprehensive approach enables facilitation of more collaborative learning and that this will generate more competent, confident and capable graduates, who are better equipped to interact in our modern challenging workplaces and our wider world.
\end{abstract}

Keywords: experiential learning, education, knowledge flow, capability development, framework, co-creation, collaboration.

\footnotetext{
${ }^{1}$ Founder, Intelligent Answers, Senior Industry Fellow, RMIT University, School of Property, Construction and Project Management, Melbourne. Email: Arthur.Shelley@RMIT.edu.au
} 
JEICOM, Vol.2, Issue 2, December 2020. Reverse Bloom: A new hybrid approach to experiential learning for a new world. Dr Arthur W Shelley.

\section{Introduction}

There are many approaches to learning, and these have reflected the nature and expectations of society at that time. Highly disciplined content-based approaches are the common and traditional method adopted widely in formal education institutions in most parts of the world. However, with changes in society and technology, new approaches to teaching and learning have emerged. All of these have their place with differing strengths and weaknesses. Some of the approaches that have gone beyond the idea of rote learning of facts and figures, have interesting characteristics worth discussing in this introduction to set some context for the new framework being introduced in this paper.

Despite their differences and contexts, many learning approaches have been influenced by the concepts of Bloom's Hierarchy (Bloom 1956), especially the modified version of the Cognitive Domain of this framework (Anderson et al 2001). Gershon (2018) highlighted that the insights being used today for learning and assessment are primarily drawn from the Cognitive domain. The other two domains discussed in the original forums, the Psychomotor (Skills aspects) and Affective (Social/Emotional aspects) have been progressively less used, possibly because detailed work on these two domains were not fully published as planned. It could also be that the shift in society towards more "scientific" (read quantitative and measurable) approaches were being preferred in the second half of last century. One issue highlighted early by Dewey (1938) with quantitative, content focused education was this it emphasises competition at the expense of collaboration. Whilst being competitive is an important success factor in life, the learning to collaborate is becoming a more important capability in our modern world (Freeth \& Caniglia, 2020; WEF 2020a).

There are some exceptions that engage in more holistic education, such as Steiner Education (Edmunds, 2004) and Montessori Method (AMI, 2020a), although these are generally considered as "alternative approaches". More recently, there has been a trend towards more holistic education (Miller et. al., 2018), with the reintroduction of experiential and social aspects into some mainstream curricula. For example, in Victoria, Australia (Victoria Dept Education \& Training, 2020) and Finland (Zilliacus, Holm, \& Sahlström, 2017) learning in real context with collaborative learning and social development are being practiced to a greater extent. This is a positive trend that this paper seeks to accelerate.

Mainstream approaches to education seem to have followed this trend, with more measurable and objective assessments being made and more standardisation of learning and teaching curricula. Whilst this has elevated the academic standards of education, it has also biased the mainstream education processes away from generating students who develop a balance of academic (theoretical cognitive) and social and life skills (psychomotor and affective capabilities) (Robinson \& Aronica, 2016). Although there is some shift towards inclusion of social elements in some places (for example Victorian Department of Education and Training 2020), it will take time to get sufficient balance across the domains.

There are examples of increasing awareness of the importance of social approaches in learning for professional workplaces. The future skills report generated by World Economic Forum (WEF, 2020a) highlights the growing importance of soft skills for success. One good example in practice is Novartis $(2018,2019)$, where the CEO, Vas Narasimhan, launched the collaborative teams initiative tagged as Unbossed. Novartis claims the program is stimulating 
innovation and speed to market through faster learning. They believe these outcomes have been generated because increased trust and social interactions enable greater leverage of diversity and this accelerates generation of new ideas. A number of public videos are available online describing the initiative and its foundations.

The World Economic Forum has recognised the importance of social capital that people bring to effective professional practice. Their report recommends revaluing, and consciously accounting for, the value this adds in the new work environment (WEF, 2020b). This is consistent with the ideas on Expansive Education developed by Engeström and Sannino (2016), which highlights quality applied learning builds both transformative agency and the ability in learners to form new theoretical concepts in practice in future social contexts. Expansive education techniques have been successfully deployed in health care as Simulation Based Education, where a depth of knowledge is needed to act in life impacting situations (Burton \& Hope, 2018).

An insightful quote from Edward de Bono is applicable in this context: "EBNE - Excellent, But Not Enough". It reinforces that knowing theories is a good thing. However only knowing is insufficient to optimise value. Learners benefit through practicing their understanding in various contexts and further refine them to perform as competent lifelong learning professionals. These examples reaffirm the author's belief that optimal future education is about opening minds and building confidence to act in uncertainty. This contrasts with content-based traditional education that focuses on filling minds with known content. The education experiences should develop the learners at the appropriate level across all three capability areas of knowing (developing understanding of principles involved in the concepts), doing (application of "hard skills") and being (social, cultural and behavioural soft skills).

Engaging people to explore possibilities in socialised exchanges around real contexts is increasingly used approach for learning (Shelley 2014; Shelley \& Goodwin, 2018; AlvarezAlvarez, Sanchez-Ruiz, Ruthven, \& Montoua Del Corte, 2019). Countries with internationally recognized high education standards, such as Finland have achieved high results in the world's education ranking (NJMED, 2018; OECD, 2018). A previous exploration of these ideas explored how Applied Social Learning Ecosystems can be used to amplify the capability development across "Knowing, Doing and Being" in a postgraduate business context in practice (Shelley \& Goodwin, 2018). This article further develops that work to create a more comprehensive framework to adapt that concept to any learning context by reversing the order of thinking in the Traditional Blooms Cognitive domain hierarchy and reintroducing the other two learning domains (Psychometric and Affective).

\section{Learning Model context}

Social learning is not a new concept - it has been discussed in the literature in various forms since the work of Dewey (1938). Dewey discussed the importance of experience, experimentation and social interactions as part of purposeful learning in what he referred to as progressive education. He highlighted that students benefit from a sense of purpose in their learning and from seeing outcomes from application of what they are learning. Holistic Learning (Miller, 1997) is a term used to refer to a comprehensive development of a person 
intellectually, emotionally and spiritually, to become a well-rounded member of society. The term has been attributed to Smuts (1927), who was advocating for deeper and more complete education enabling self-actualisation. More recently, the history of, and concepts involved, in holistic education approaches have been reviewed by Miller et. al., (2018).

There is significant literature support for experiential learning approaches (Slavich, \& Zimbardo, 2012; Kolb \& Kolb, 2017). Some of these differ in the how and why it should be facilitated (Schenck \& Cruickshank, 2015) and others advocate broader curriculum to include social development in addition to the academic and cognitive aspects (Hayden \& McIntosh, 2018). Despite these emerging and ongoing dialogues, Kolb \& Kolb (2017) highlight that experiential learning has received significant support in ongoing professional development across many professional disciplines. The experiences in the medical profession support this statement (Yardley, Teunissen \& Dornan, 2012; Chamane \& Mashamba-Thompson, 2019).

This article acknowledges the depth and breadth of literature on a diversity of learning approaches being advocated, and that all have their strengths and weaknesses. This article aims to connect several of the practical insights on experiential learning into a practical framework to guide learning facilitators who wish to engage their learners through a more collaborative and social experience that is inclusive, enjoyable and beneficial. A new framework is proposed that assimilates many elements from a range of existing models to embed social, cognitive and affective aspects into the learning experience. This framework can be experimented with by educational practitioners to further evolve our options to accelerate learning and enhance learning outcomes. Although not initially designed for remote learning, the framework is adaptable to virtual learning experiences. During the period when the COVID-19 pandemic has disrupted education globally (Bonk, et al., 2020), the framework has been used to enable facilitation of experiential learning activities originally designed for face to face, by adapting interventions to make on-line learning more interactive.

The original elements of Bloom's Hierarchy (Bloom 1956) indicated that learning was built through six levels of learning in increasing richness (Knowledge, Comprehension, Application, Analysis, Synthesis and Evaluation). This suggested a process that started from a foundation of knowledge to develop understanding which enables application, from which learners can synthesise insight and evaluate the impacts and meaning of their learning. This hierarchy has been used extensively, with some others suggesting equivalent words or aligned replacement verbs for the stages. A widely accepted modified version of this framework was created by Anderson et al (2001), based on verbs and switching the order of the last two elements. This version describes the outcomes the learner was able to perform at for each of the levels, thus highlighting the actionable aspect of learning and the importance of it being learner centered. The modified hierarchy read: Remember, Understand, Apply, Analyse, Evaluate, Create). A later revision (Shelley, 2017) changed create to co-create to highlight that collaborative learning enables incorporating a range of perspectives is superior to individual development of concepts and capabilities. This paper suggests that although these latest six elements remain valid, more effective learning can be achieved by reversing 
JEICOM, Vol.2, Issue 2, December 2020. Reverse Bloom: A new hybrid approach to experiential learning for a new world. Dr Arthur W Shelley.

their order and reintroducing the Affective and Psychomotor domains into collaborative learning experiences.

\section{Introducing the Reverse Bloom Learning Framework (RBLF)}

Bloom's hierarchy of learning (Bloom et al., 1956; Bloom, Hastings, \& Madaus, 1971) suggests the depth of learning increases as learners progress from Knowledge, through Understanding, Application, Analysis, Synthesis to Evaluation. Versions of this have been the foundation of teaching design, delivery and assessment for half a century. Bloom originally suggested three domains: Cognitive, Psychometric and Affective. However, only the Cognitive domain remained in active use by most teachers and learning design in mainstream formal education (Gershon, 2018). This results in most learning being focused on thinking about content and assessment methods primarily quantitative. This may generate academically sound graduates, but it does not necessarily develop well rounded professionals. Figure 1 introduces a new approach, the "Reverse Bloom Learning Framework" (RBLF). The RBLF provides an alternative way of interacting and applying these elements. Rather than using these elements as a linear hierarchy to transfer existing knowledge to build capabilities, as is common in the education profession, this new framework challenges learning professionals to apply them as iterative social activities working from the top down to generate knowledge.

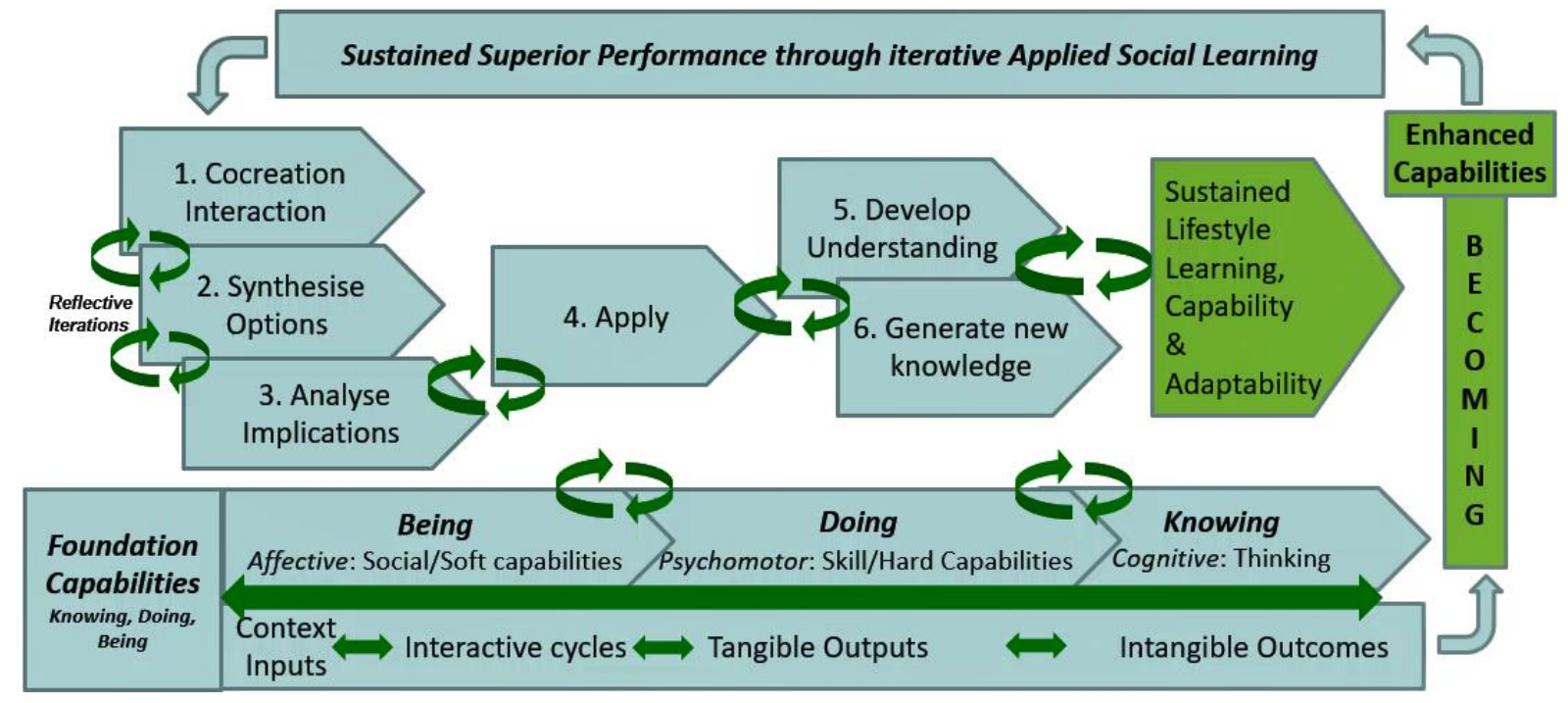

Figure 1 Reverse Bloom Learning Framework

Note: Cyclic arrows represent iterations of reflection to deepen learning within activities.

The RBLF incorporates all three Bloom domains and proposes a reversal of the "order" of the cognitive domain. That is, from co-creation "down" to knowledge, rather than the traditional approach from knowledge up to creation. This new approach applies the cognitive domain elements through experiences in iterative social learning cycles. What this means is (with a small exposure to some insights first), learners explore possibilities and implications of a real context through co-creative interactivities. This enables all people involved to synthesise and analyse implications as they deconstruct the challenge presented (RBLF actions 1-3). Once learners design or prototype some options, they apply them (RBLF action 4) to understand 
the best possibilities for further use. Reflections between the learners before, during and after each action stimulates socialization of the possibilities, which further expands their understanding (RBLF action/outcome 5). This deeper and wider understanding leads to the generation of new knowledge (RBLF action/outcome 6) and triggering professional processes like creativity and innovation.

In the RBLF approach, much of the knowledge generated is new, rather than just a transfer of prior existing knowledge, as each person can perceive the concept in a different way. This highlights why reflective conversations about their perspectives and understanding are important throughout the whole process. It enables all learners to benefit, from the understanding of everyone involved, not just from their own insights. They could possibly learn from reflections of prior learners as well, if artefacts for those experiences have also been kept. These reflective conversations happen throughout all cycles in the process to generate not just an understanding of the original concept, but a greater set of insights and new possibilities for adaption of the concepts into other options or fields. This cyclic, reflective, and social learning in real context is aligned with the Expansive Education (EE) approach discussed by Engeström \& Sannino (2016). EE cycles involve a range of iterative activities taking context and culture into account, to generate social change. The flow of EE activities are; questioning, analysis, modelling new options, evaluating these, implementing options in practice and finally reflecting on outcomes to embed insights into new practice.

\section{Design of learning activities and assessments for RBLF approach}

The RBLF is designed to be flexible, so that the principles of this learning approach can be applied to any level of learner (young children through to executives). The significant factor for design consideration of both activities and assessments is what level of capability does the learners already have and what new or elevated capabilities are to be developed. These steps are aligned with standard approaches to intervention and assessment design (Gershon, 2018; Biggs \& Tang, 2011), although with more emphasis on socialization and collaboration, and monitoring application of learning during the learning experience. This also highlights the benefits of support for ongoing development of capabilities beyond the formal learning experiences into professional practice, something outside the scope of most formal learning.

The generic steps to design a learning intervention and assessment are:

1. Assess the foundational capabilities (Knowledge, Skills and Social/Behavioral) of the learners to determine current and desired states and define the gap.

2. Consider the context of the learning and a real challenge to be resolved within this by the learners.

3. Define learning objectives across all three domains (Cognitive, Psychomotor and Affective) based on the learning outcomes to fill the capabilities gap.

4. Create a series of learning activities that are inclusive social experiences in which learners explore possibilities relevant to the challenge context.

5. Construct an assessment rubric that clarifies the changes to be demonstrated through the learning. Note this is likely to include some subjective measures of the quality of the capabilities. This is inevitable in social systems and happens all the time in workplaces. The rubric should be as explicit as possible to guide the learners, but 
not so rigid to disallow unpredicted creative solution the facilitator has not considered. Remembering that the RBLF acknowledges the value of co-creating new possibilities in addition to existing knowledge, within the context.

6. Facilitate learning interventions that provoke divergent thinking and social exchanges around possibilities and prioritise actions.

7. Assess outputs and outcomes against the defined learning criteria

8. Provide meaningful and balanced individualised feedback. Feedback is optimal when it highlights the aspects that have been done well (demonstrated capabilities against planned learning outcomes defined in the rubric) and the aspects that they could have done better (learning gaps not met as defined by the rubric). If the planned learning is ongoing, as is usually the case in formal learning, the learner proceeds to the next learning activity. That is, back to step 1 for the new set of learning outcomes and activities.

9. Facilitate a reflective conversation with the learner is sometimes appropriate where the feedback is not understood or needs to be clarified.

Extend the learning into professional practice. Ongoing assessment (beyond the planned learning program - after "graduation") helps to reinforce, amplify and extend sustained learning. Follow up conversations with the learners after the formal parts of the learning has been "completed" enables them to consciously reflect on their progress. Assessing the impacts generated when capabilities are put into professional practice is helpful to refine capabilities. This encourages ongoing use of the learned capabilities to continue their development. This is where optimal return on investment comes for learning. When this is not done capabilities may not be put into practice and capabilities reduce over time, along with the potential value. Programs such as coaching and mentoring can assist with the motivation to ensure optimal return is achieved from the learning investment for all parties.

\section{A starter on RBLF principles}

Principles of learning for this framework are not significantly different from those in the general learning literature. However, more emphasis is applied to social interactions and iterative action learning. No doubt, as others experiment with the RBLF, more principles will emerge. The list below is not meant to be comprehensive, but offers a useful set of principles to begin designing and implementing your RBLF interactions:

- Engage to open minds rather than fill them, emphasise context over content.

- Aim to co-create a range of options rather than finding an existing answer.

- Embed iterative collaborative cycles of divergent and convergent thinking, laced with social challenges to explore the emotional and human aspects of the topics.

- Reinforce that creativity is a critical part of learning, as are sense making and play.

- Stimulate Creative Friction (constructive challenges to deliberately clash alternatives to co-create new possibilities) as a key driver.

- Proactively facilitate learner-centered experiences, with balanced cognitive, affective and psychomotor aspects. 
- Optimal learning builds the capabilities and confidence of the learner to safely enter the unknown and explore (expanding their comfort zone).

- Social connections and trusted relationships should be outcomes of the learning

- Invest heavily in reflective conversations through collaborative cycles to share perspectives.

- Invest in designs and facilitation that are inclusive of all perspectives.

- Aim to develop well-rounded people who feel competent to generate value from applying collaborative learning to continue to refine their capabilities ongoing.

Share insights and learnings from use of the RBLF with other practitioners to amplify what we can collectively achieve to further mature the approach.

\section{Discussion}

Some elements of holistic approaches and progressive learning have been embedded into a range of experiential learning approaches including, Student-centered Learning, Problembased Learning and Project-based Learning. Benefits from these alternative approaches have been described by educators exploring which elements generate high quality learning outcomes (Miller et. al., 2018). There is alignment between some aspects of these approaches and methods used in some successful non-mainstream educational institutions, such as Steiner Education (Edmunds, 2004) and the Association Montessori Internationale (AMI, 2020a). Montessori (2014) was an educational leader ahead of her time advocating for social, creative and holistic educational experiences to prepare students to enable them to become transforming agents in society leading to a more harmonious and peaceful world (AMI, 2020b). Some of the ideas have been incorporated into creative experiential activities in commercial professional development, for example Serious Play (Schulz et, al., 2015) and Experiential Workshops (MTA, 2020).

Historically, there has not been a single learning framework that combines the key insights of these concepts into an interconnected flow that is easily incorporated into mainstream education at all levels. The Reverse Bloom Learning Framework offers an opportunity to achieve this in one inclusive framework. The RBLF offers an adaptable approach for learning that incorporates the three Bloom domains into a series of iterative and interdependent learning experiences. It combines the collective perspectives of the learners as they explore possibilities around real challenges. This collaborative and social interaction stimulates cocreation of a range of potential options. It also leads to deeper understanding and the generation of new knowledge (effectively the exact reverse of the order of activities in the traditional use of Bloom's learning hierarchy). The suggested order of reversal applies to the modified (actionionable outcomes based) version as shown in Figure 2 (Shelley, 2017). Traditionally Bloms Hierarchy is taught from bottom up; Remember (knowledge) up to Create (or Co-create in this version). The reverse Bloom recommends top down; Co-Create, Evaluate, Analyse, Apply, Understand to Generate new knowledge (a shift away from just remember, or existing knowledge, in earlier versions). 


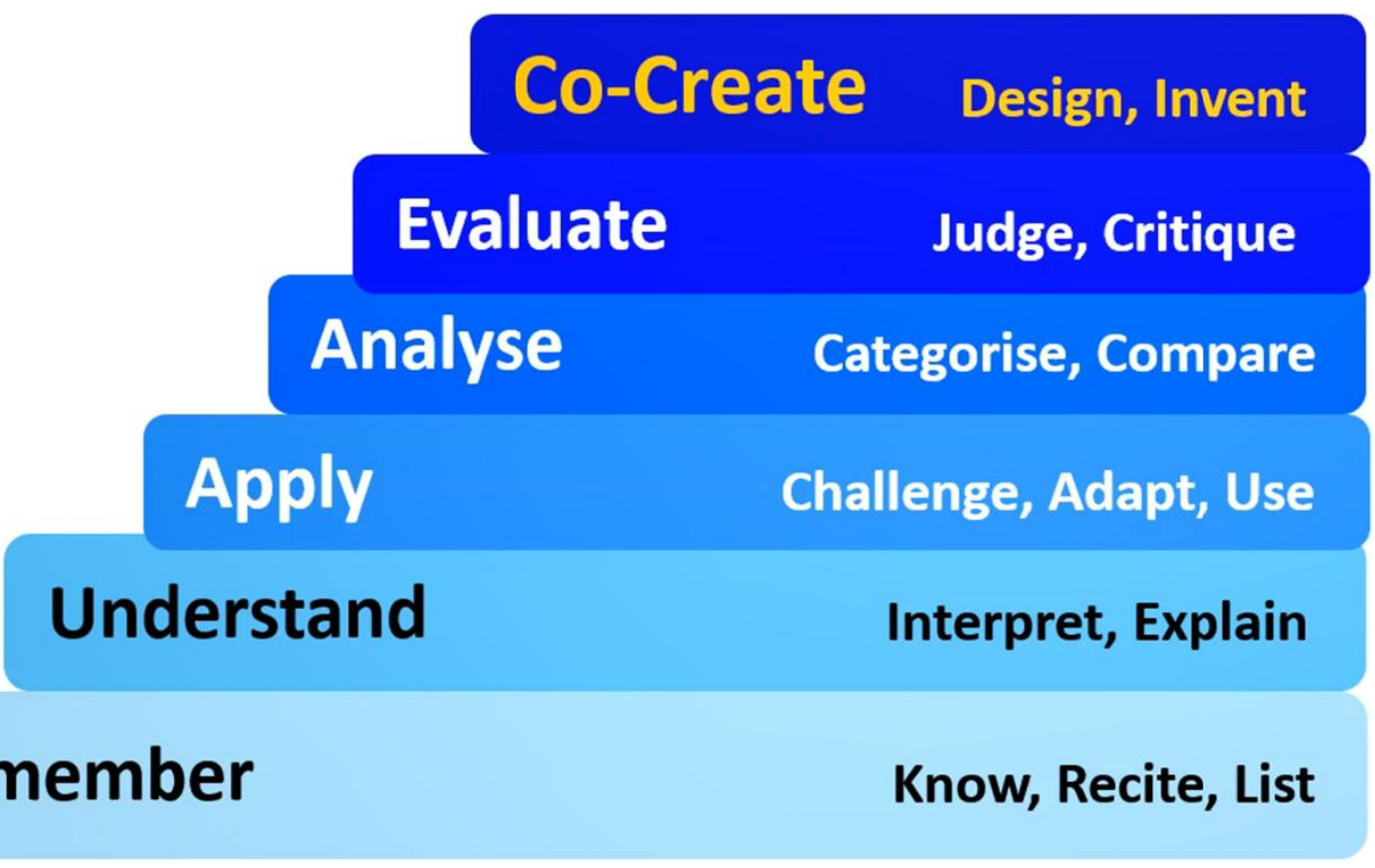

Figure 2 Adapted verb-based version of Blooms Hierarchy of Learning (Shelley, 2017)

The name Reverse Bloom Learning Framework (RBLF) was chosen to respect the many existing models that leverage this concept and demonstrate this is an adaptation of how, rather than a rejection of what. However, it also highlights that it reverses the traditional order in the way the learning is done. RBLF involves actively engaging participants in learning interventions without prior coverage of the content (although a flipped classroom approach can complement this to further accelerate the learning by exposure to some content if desired). Although many of the concepts embedded into the RBLF already existed, this approach simplifies a process for learning facilitators of all leaves of experience to implement complex learning, in what appears to be a simple engaging environment. Learners perform better when they are actively involved in the learning process and are more motivated when it is inclusive and enjoyable (Shelley, Ooi, \& Brown, 2019). COVID-19 has generated a time of reflection around how we educate and why (Butler-Henderson, et al., 2020; Crawford et al., 2020).

This is a timely constructive challenge of what works best for our learners. There is emerging support for more socially constructed learning experiences based on collective knowledge and intelligence (Kolb \& Kolb, 2017; Shelley \& Goodwin, 2018; Kefalaki \& Diamantidaki, 2020), especially to consider improvements in remote learning (Downes, 2018) and mobile learning (Lim, Shelley, \& Heo, 2019). By including these aspects into the learning experience, the RBLF approach reconnects all three domains of Bloom's original approach (Cognitive, Psychomotor and Affective), providing a more holistic learning experience (Biggs, Harris, \& Rudolph, 2019).

If you look closely enough you can see some of the principles and elements of RBLF in some processes developed independently of learning theory. Practices like Design Thinking (Brown, 2009) and Agile Project Management (Morris \& Ma, 2014) are based on iterative 
cycles of divergent and convergent interactions. This is because people developing and facilitating such processes know that it works in practice. They do it because it achieves the outcomes they desire and are often unaware that it is aligned with learning principles. This simply reflects a natural style of problem-solving they have learned through practice, despite them not consciously considering learning theory literature. The RBLF provides such practitioners with a simple approach to achieve these outcomes with a little methodology embedded to achieve more consistent outcomes as it provides them with a more solid foundation and a generic process to follow. We do not seek to make learning practitioners out of professionals from other fields. However, embedding learning principles into all fields of pursuit is increasingly important in an ever-changing world.

Throughout the history of learning research and practice many examples of experiential and or social learning models, have been built around iterative cycles of investigation and inclusion of a range of perspectives. Some of the methods described that include aspects of this approach include; action learning (Revans, 1980), student-centered learning, (Wright, 2011), problem-based learning (Bethell \& Morgan 2011), and social learning (Van Epp, \& Garside, 2014). More widely the principles have been involved in the corporate professional development area (Keys, 1994; Schaefer, Vanderbilt, Cason, \& Navedo, 2011), and in design of engaging games (Kolb, \& Kolb, 2009).

Creating a social environment in which learners engage around challenges by taking deliberately different perspectives is a practice gaining wider application (Baker, Jensen, \& Kolb, 2002; Shelley \& Goodwin, 2018; Alvarez-Alvarez, Sanchez-Ruiz, Ruthven, \& Montoua Del Corte, 2019). Kolb and Kolb (2017, p 36) stated "Good conversation is more likely to occur in spaces that integrate thinking and feeling, talking and listening, leadership and solidarity, recognition of individuality and relatedness, and discursive and recursive processes." Recognising the right type of conversation for the learning moment is critical. There are times for the divergent exploratory conversation (leveraging creativity and brainstorming to create options) and a time for the convergent conversations (leveraging critical thinking, problem solving capabilities and prioritising options into a reduced list and form recommendations).

Since the development of the internet and digital learning opportunities, new learning preferences have emerged, especially around virtual and digital social contexts (Sousa-Vieira, et. al., 2016). These authors suggested that traditional education systems would benefit from evolving their practices to leverage these new approaches. Social Learning Strategies can be effective, although they are dependent on knowing who the best people are in the network to learn from (Heyes, 2016). Engaging learners in a social community is learning approach that can nurture learning and help address challenges faced in higher education (Culver and Bertram, 2017). Social engagement is harder to achieve in virtual environments, as the online environment is not as conducive to interactive conversations as face to face. Ironically, comfort levels with remote interactions have been increased by the COVID-19 pandemic (Bonk, et al., 2020), as people have been forced to become more familiar with on-line 
interactions in the forced remote workplace and education situations. Technology has improved dramatically as well, since technology providers actively compete for a bigger share of this suddenly accelerated demand. This has generated a wave of development, increased capabilities of both learning facilitators and learners that make remote learning a better experience for all involved.

\section{Some examples of activities that embed RBLF principles in virtual learning}

Technology is developing fast for virtual learning that goes beyond teaching content, especially in the area of play as a means of collaborative learning (Essmiller, 2020). The two examples described here are activities that have been creatively adapted to interactive online versions. Although designed and tested for face-to-face education before the COVID19 pandemic, these activities have been adapted to virtual interactions. The post-COVID-19 world will inevitably involve much more online learning (hopefully interactive and not just reading content), so adapting social learning interactions remains a priority.

Virtual Escape Room

Escape rooms have become a popular entertainment activity in recent years. Instead of a physical experience, the concept has been adapted to provide virtual learning by using breakout groups in on-line tools. Student groups move across a series of breakout rooms and need to solve some problems before they can be moved to the next "room". The problems to be solved involve demonstrating knowledge related to the stated learning outcomes. Visual clues and other creative or cryptic questions can be created to stimulate social interaction between members of the group.

The concept can be used as a starter in each lesson to highlight what learners can solve quickly and what they struggle with, thereby highlighting what topics need more attention. An advancement is gamification of the experience by keeping a "team scorecard" as they learners progress through series of sessions. Care should be taken to ensure that gamification motivates participants in a constructive way and does not become over competitive. Collaboration skills are important to social success, so reinforcing competition exclusively at the expense of collaboration is not a desirable approach. The development of collaboration games is starting to gain acceptance outside of learning and this makes a good trend to encourage further learning. Ways of implementing virtual escape room are only limited by the reach of your imagination.

\section{Co-created Projects Worth DOING (CPWD)}

CPWD is a process designed to generate ideas from all participants in a specified "action format" and then clustering these into projects for implementation (Shelley, 2019). The process has been used in executive education workshops to generate real project options for participants, which have generated social benefits. Some examples of the initiatives coming from such workshops are; a Chinese leadership delegation developed initiatives for pollution mitigation, a Vietnamese delegation created several projects to address the needs of a minority ethnic group, and an Australian based charitable organization were assisted to accelerate innovation in a workplace for people with disabilities. This process structures context-based actions into phrases starting with a verb to precisely define the next steps for 
success, a process aligned with attention to verbs in the SOLO Learning Taxonomy (Biggs, Harris, \& Rudolph, 2019).

The Reverse Bloom Learning Framework and the shared activities in this paper have emerged through creative practices that have been informed by the rich history of educational literature outlined above. It is informed by the experimental approach to project-based learning in real contexts and reflective practice on shared experiences (Shelley \& Goodwin, 2018). In addition, insights have been taken from evolving novel approaches to learning (Ferguson et al., 2017). This framework when used in association with the principles outlined and inclusive interventions like those listed in this article, creates positive learning experiences (Shelley \& Goodwin, 2018).

\section{Conclusions}

The Reverse Bloom Learning Framework introduced in this article is an adaptation that combines a number of learning principles and models. Combined with the learning principles, design insights and examples shared in this article, the RBLF can be a powerful learning experience developing capabilities across all three learning domains. Although the RBLF is novel, it leverages strong interdisciplinary literature and evolving concepts across the history of education and learning practices. The RBLF simply connect these existing concepts to extend experiential approaches into an easily understood framework that enables facilitation of collaborative and social learning experiences. Facilitating learning interactions through the reverse direction, compared to traditional education approaches, generates a more comprehensive learning experience across the three key aspects (domains) of quality learning; knowing (cognitive), Doing (psychomotor) and Being (affective). The approach is flexible to enable learners of all capability levels to engage in (based on an assessment of their prior knowledge and experiences). This makes it accessible for educational practitioners to adopt and adapt to a wide range of learners by designing learning activities that align the principles of the approach with the desired learning outcomes. Reversing the mindset to experience co-creative interactions, before formalising deeper exploration of the content, provides a strong foundation for living, and creating options for challenges, in our modern virtual and VUCA (Volatile, Uncertain, Complex and Ambiguous) world.

The example techniques and concepts shared here are just the beginning of what is possible with the RBLF. Practitioners are encouraged to experiment with the concepts and share their experiences to further evolve our collective understanding. Collaborating on further development of this approach can engage learners to remain involved in ongoing learning experiences, because they love it and see value in lifestyle learning (Shelley and Goodwin, 2018). 
JEICOM, Vol.2, Issue 2, December 2020. Reverse Bloom: A new hybrid approach to experiential learning for a new world. Dr Arthur W Shelley.

\section{References}

Alvarez-Alvarez, C., Sanchez-Ruiz, L., Ruthven, A., \& Montoua Del Corte, J. (2019). Innovating in University Teaching Through Classroom Interaction. Journal of Education, Innovation, and Communication, 1(1), 8-18.

Anderson, L. W., \& Krathwohl, D. R. (Eds.). (2001). Taxonomy for Learning, Teaching, and Assessing: A Revision of Bloom's Taxonomy of Educational Objectives (Abridged). New York, NY: Addison Wesley Longman, Inc.

AMI Association Montessori Internationale. (2020a). About AMI https://montessoriami.org/about-montessori

AMI Association Montessori Internationale. (2020b). AMI Vision and Mission https://montessori-ami.org/about-ami/our-mission

Baker, A. C., Jensen, P. J., \& Kolb, D.A., (2002). Conversational Learning: An Experiential Approach to Knowledge Creation. Westport, CT: Quorum Books.

Bethell, S. \& Morgan, K. (2011). Problem-based and Experiential Learning: Engaging Students in an Undergraduate Physical Education Module. Journal of Hospitality, Leisure, Sport and Tourism Education, 10(1), 128-34.

Biggs, J. B. \& Tang, C. (2011) Teaching for Quality Learning at University, Buckingham: Open University Press/McGraw Hill.

Biggs, J., Harris, C. W., \& Rudolph, J. (2019). Teaching for quality learning at changing universities. A tour de force of modern education history - an interview with Professor John Biggs. Journal of Applied Learning and Teaching, 2(1), 54-62.

Bloom, B. S., Englehart, M. D., Furst, E. J., Hill, W. H., \& Krathwohl, D. R. (1956). The Taxonomy of Educational Objectives, The Classification of Educational Goals, Handbook 1: Cognitive Domain. New York: David McKay Company Inc.

Bloom, B. S., Hastings, J. T., \& Madaus, G. F. (1971). Handbook on Formative and Summative Evaluation of Student Learning. New York, NY, USA: McGraw-Hill Book Company.

Bonk, R. J., Kefalaki, M., Rudolph, J., Diamantidaki, F., Munro, C. R., Karanicolas, S., et al. (2020). Pedagogy in the Time of Pandemic: From Localisation to Glocalisation Journal of Education, Innovation, and Communication, Special Issue, June 2020, 17-64.

Brown, T. (2009). Change by Design: How Design Thinking Transforms Organizations and Inspires Innovation. New York, NY: HarperBusiness.

Burton, R., \& Hope, A. (2018). Simulation based education and expansive learning in health professional education: A discussion. Journal of Applied Learning and Teaching, 1(1), 25-34.

Butler-Henderson, K., Crawford, J., Rudolph, J., Lalani, K., \& Sabu, K. M. (2020). COVID19 in Higher Education Literature Database (CHELD V1): An open access systematic literature review database with coding rules. Journal of Applied Learning and Teaching, 3(3), DOI: https://doi.org/10.37074/jalt.2020.3.2.11.

Chamane, N., \& Mashamba-Thompson, T. P. (2019). Experiential Learning Curriculum Delivery Approach for Quality Improvement in Resource Limited Settings: Mobile 
JEICOM, Vol.2, Issue 2, December 2020. Reverse Bloom: A new hybrid approach to experiential learning for a new world. Dr Arthur W Shelley.

Learning for Point-of-Care Technologies Global Journal of Health Science, 11(13), 158-166.

Crawford, J., Butler-Henderson, K. Rudolph, J., Malkawi, B., Glowatz, M., Burton, R., Magni, P., \& Lam, S. (2020). COVID-19: 20 countries' higher education intra-period digital pedagogy responses. Journal of Applied Learning \& Teaching, 3(1) 9-28.

Culver, D. M., \& Bertram, R. (2017). Learning Value and Identity Formation: Social Learning and the Graduate Studies Experience. In J. McDonald \& A. Cater-Steel (Eds.), Implementing Communities of Practice in Higher Education. Singapore: Springer.

Dewey, J. (1938). Experience \& Education. New York: Kappa Delta Pi.

Downes, S. (2018). Modernised learning delivery strategies: The Canada School of Public Service technology integration project. Journal of Applied Learning \& Teaching, 1(2), $15-25$.

Edmunds, F. (2004). An Introduction to Steiner Education: The Waldorf School. Forest Row: Sophia Books

Engeström, Y., \& Sannino, A. (2016). Expansive learning on the move: insights from ongoing research / El aprendizaje expansivo en movimiento: aportaciones de la investigación en curso. Infancia y Aprendizaje, 39(3), 401-435.

Essmiller, K. (2020). Learning Through Play. In B. Hokanson, G. Clinton, A. Tawfik, A. Grincewicz \& M. Schmidt (Eds.), Educational Technology Beyond Content. Educational Communications and Technology: Issues and Innovations. Springer International Publishing.

Freeth, R., Caniglia, G. (2020). Learning to collaborate while collaborating: advancing interdisciplinary sustainability research. Sustainability Science 15, 247-261.

Ferguson, R., Barzilai, S., Ben-Zvi, D., Chinn, C. A., Herodotou, C., Hod, Y., . . . Whitelock, D. (2017). Innovating Pedagogy 2017: Open University Innovation Report 6. Milton Keynes: The Open University, UK.

Gershon, M. (2018). How to use Bloom's Taxonomy in the Classroom: The Complete Guide. West Palm Beach, FL: Learning Sciences International.

Hayden, M., \& McIntosh, S. (2018). International education: the transformative potential of experiential learning. Oxford Review of Education 44(4), 403-413.

Heyes, C. (2016). Who Knows? Metacognitive Social Learning Strategies. Trends in Cognitive Sciences, 20(3), 204-213.

Kefalaki, M. K., \& Diamantidaki, F. (2020). Nurturing Collective Knowledge and Intelligence: Social phenomena and implications for practice. Journal of Education, Innovation, and Communication, 2(1), 7-9.

Keys, L. (1994). Action Learning: Executive Development of Choice for the 1990s. Journal of Management Development, 13(8), 50-56.

Kolb, A. Y., \& Kolb, D. A. (2017). Experiential Learning Theory as a Guide for Experiential Educators in Higher Education. Experiential Learning \& Teaching in Higher Education, 1(1 Article 7), 7-44.

Kolb, A., \& Kolb, D. (2009). The learning way: Meta-cognitive aspects of experiential learning. Simulation \& Gaming, 40, 297-327. 
JEICOM, Vol.2, Issue 2, December 2020. Reverse Bloom: A new hybrid approach to experiential learning for a new world. Dr Arthur W Shelley.

Lim, G., Shelley, A. W., \& Heo, D. (2019). The regulation of learning and co-creation of new knowledge in mobile learning. Knowledge Management \& E-Learning, 11(4), 449-484.

Miller, R. (1997). What Are Schools For? Holistic Education in American Culture, 3rd Edition. Brandon, VT: Holistic Education Press.

Miller, J.P. Nigh, K., Crowell, S., Novak, B., Binder, M. J. (2018). International Handbook of Holistic Education. New Your, NY: Routledge.

Montessori, M. (2014). The Montessori Method. New Brunswick, NJ. Transaction Publishers.

Morris, L., \& Ma, M. (2014). Agile Innovation: The Revolutionary Approach to Accelerate Success, Inspire Engagement, and Ignite Creativity. Hoboken, NJ: John Wiley and Sons.

MTA (2020) Experiential Learning Knowledgebase. Retrieved from https://www.experientiallearning.org/knowledge-centre/

NJMED New Jersey Minority Educational Development (2018). World's Top Education Systems. Retrieved from https://worldtop20.org/worldbesteducationsystem.

Novartis (2018) Vas Narasimhan and author Dan Pink talk culture and leadership. Retrieved from https://youtu.be/PGz2MJKIkIk

Novartis (2019) Talking culture transformation with Vas Narasimhan and Adam Grant. Retrieved from https://youtu.be/hGwSvD7thgY

OECD (2018). Education at a glance. Retrieved from http://www.oecd.org/education/education-at-a-glance/

Revans, R.W. (1980). Action Learning: New Techniques for Management.

London: Blond \& Briggs.

Robinson, K., \& Aronica, L. (2016) Creative Schools. Penguin Books.

Schaefer, J. J., Vanderbilt, A., Cason, C.L. \& Navedo, D., (2011). Literature Review: Instructional Design and Pedagogy Science in Healthcare Simulation. Simulation in Healthcare, 6(7), S30-S41.

Schenck, J., \& Cruickshank, J. (2015). Evolving Kolb: Experiential Education in the Age of Neuroscience. Journal of Experiential Education, 38(1), 73-95.

Shelley, A. W. (2014). Active learning innovations in knowledge management education generate higher quality learning outcomes Journal of Entrepreneurship Management and Innovation, 10(1), 129-145.

Shelley, A. W. (2017). KNOWledge SUCCESSion. Sustained performance and capability growth through strategic knowledge projects. New York, NY: Business Expert Press.

Shelley, A. W. (2020). Cocreated Projects Worth Doing. Journal Technology and Governance, 1(1).

Shelley, A. W., \& Goodwin, D. (2018). Optimising learning outcomes through social cocreation of new knowledge in real-life client challenges. Journal of Applied Learning \& Teaching, 1(2), 26-37.

Shelley, B., Ooi, C. S., \& Brown, N. (2019). Playful learning? An extreme comparison of the Children's University in Malaysia and in Australia. Journal of Applied Learning \& Teaching, 2(1), 16-23. 
JEICOM, Vol.2, Issue 2, December 2020. Reverse Bloom: A new hybrid approach to experiential learning for a new world. Dr Arthur W Shelley.

Slavich, G. M., \& Zimbardo, P. G. (2012). Transformational Teaching: Theoretical Underpinnings, Basic Principles, and Core Methods. Educational Psychology Review, 24(4), 569-608.

Smuts, J.C. (1926). Holism and Evolution. London: Macmillan \& Co.

Sousa-Vieira, M. E., López-Ardao, J. C., Fernández-Veiga, M., Rodríguez-Pérez, M., \& Herrería-Alonso, S. (2016). An open source platform for using gamification and social learning methodologies in engineering education: Design and experience. Computer Applications in Engineering Education, 24, 813-826.

Schulz, K.-P., Geithner, S., Woelfel, C., \& Krzywinski, J. (2015). Toolkit-Based Modelling and Serious Play as Means to Foster Creativity in Innovation Processes. Creativity and Innovation Management, 24(2), 323-340.

Van Epp, M., \& Garside, B. (2014). Monitoring and Evaluating Social Learning: A Framework for Cross-Initiative Application. CCAFS Working Paper no. 98. Copenhagen, Denmark: CGIAR Research Program on Climate Change, Agriculture and Food Security (CCAFS).

Victorian Department of Education and Training (2020). The Victorian Curriculum F-10. Retrieved from https://victoriancurriculum.vcaa.vic.edu.au/

WEF (2020a). World Economic Forum. Future of Jobs Report. Retrieved from http://www3.weforum.org/docs/WEF_Future_of_Jobs_2020.pdf

WEF (2020b). World Economic Forum. Human Capital as an Asset: An Accounting Framework to Reset the Value of Talent in the New World of Work. Retrieved from https://www.weforum.org/reports/human-capital-as-an-asset-anaccounting-framework-to-reset-the-value-of-talent-in-the-new-world-of-work

Wright, G. B., (2011). Student-Centered Learning in Higher Education. International Journal of Teaching and Learning in Higher Education, 23(3), 92-97.

Yardley, S., Teunissen, P. W., \& Dornan, T. (2012). Experiential learning: transforming theory into practice. Medical Teacher, 34(2), 161-164.

Zilliacus, H., Holm, G., \& Sahlström, F. (2017). Taking steps towards institutionalising multicultural education - The national curriculum of Finland. Multicultural Education Review, 9(4), 231-248.

This journal provides immediate open access to its content on the principle that making research freely available to the public supports a greater global exchange of knowledge. You can Share - Copy and redistribute the material in any medium or format for any purpose, even commercially, under the terms of the Creative Commons Attribution License (CC BY). The use, distribution or reproduction is permitted, provided the original author(s) and the copyright owner(s) are credited and that the original publication in this journal is cited, in accordance with accepted academic practice. No use, distribution or reproduction is permitted which does not comply with these terms. Copyright for this article: () 2020 Dr Arthur W Shelley. 